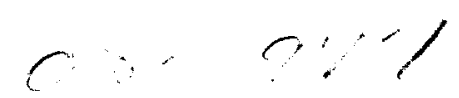

\title{
Thermal Modeling and Analysis of a Cryogenic Tank Design Exposed to Extreme Heating Profiles
}

Craig A. Stephens and Gregory J. Hanna

PRC Inc., Edwards, California

Prepared for

NASA Dryden Flight Research Facility

Edwards, California

Under Contract NAS 2-12722

1991

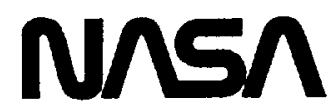

National Aeronautics and

Space Administration

Dryden Filght Research Facility

Edwards, California 93523-0273 



\section{THERMAL MODELING AND ANALYSIS OF A CRYOGENIC TANK DESIGN EXPOSED TO EXTREME HEATING PROFILES}

\author{
Craig A. Stephens* \\ PRC Inc. \\ Edwards, California \\ Gregory J. Hanna ** \\ Hanna Technology Resources \\ Boulder, Colorado
}

\begin{abstract}
A cryogenic test article, the Generic Research Cryogenic Tank, was designed to qualitatively simulate the thermal response of transatmospheric vehicle fuel tanks exposed to the environment of hypersonic flight. One-dimensional and two-dimensional finite-difference thermal models were developed to simulate the thermal response and assist in the design of the Generic Research Cryogenic Tank. The onedimensional thermal analysis determined the required insulation thickness to meet the thermal design criteria and located the purge jacket to eliminate the liquefaction of air. The two-dimensional thermal analysis predicted the temperature gradients developed within the pressure-vessel wall, estimated the cryogen boiloff, and showed the effects the ullage condition has on pressure-vessel temperatures. The degree of ullage mixing, location of the applied high-temperature profile, and the purge gas influence on insulation thermal conductivity had significant effects on the thermal behavior of the Generic Research Cryogenic Tank. In addition to analysis results, a description of the Generic Research Cryogenic Tank and the role it will play in future thermal structures and transatmospheric vehicle research at the NASA Dryden Flight Research Facility is presented.
\end{abstract}

\footnotetext{
"Mechanical engineer, member AlAA.

* Consulting engineer, member AIAA.

Copyright (C1991 by the American Institute of Aeronautics and Astronautics, Inc. No copyright is asserted in the United States under Title 17, U.S. Code. The U.S. Government has a royalty-free license to exercise all rights under the copyright claimed herein for Governmental purposes. All other rights are reserved by the copyright owner.
}

\section{Nomenclature}

\begin{tabular}{|c|c|}
\hline$c_{p}$ & specific heat, BTU/lbm ${ }^{\circ} \mathrm{R}$ \\
\hline $\mathrm{Gr}$ & Grashof number $=g \beta\left(T_{W}-T_{V}\right) x^{3} / \nu^{2}$ \\
\hline $\mathrm{GH}_{2}$ & gaseous hydrogen \\
\hline GRCT & Generic Research Cryogenic Tank \\
\hline & gravitational constant, $32.2 \mathrm{ft} / \mathrm{sec}^{2}$ \\
\hline HA $85 \mathrm{M}$ & $\begin{array}{l}\text { liquid Hydrogen test case, high temper- } \\
\text { ature applied uniformly to All heat } \\
\text { shield quadrants, } 85 \text {-percent fill } \\
\text { level, Mixed ullage condition }\end{array}$ \\
\hline
\end{tabular}

HA85S liquid Hydrogen test case, high temperature applied uniformly to All heat shield quadrants, 85-percent fill level, Stratified ullage condition

HB85M liquid Hydrogen test case, high temperature applied to the Bottom heat shield quadrant, 85-percent fill level, Mixed ullage condition

HB85S liquid Hydrogen test case, high temperature applied to the Bottom heat shield quadrant, 85-percent fill level, Stratified ullage condition

HT85M liquid Hydrogen test case, high temperature applied to the Top heat shield quadrant, 85-percent fill level, Mixed ullage condition

HT85S liquid Hydrogen test case, high temperature applied to the Top heat shield quadrant, 85-percent fill level, Stratified ullage condition convective heat transfer coefficient, $\mathrm{BTU} / \mathrm{ft}^{2} \sec ^{\circ} \mathrm{R}$ 


\begin{tabular}{|c|c|}
\hline$k$ & thermal conductivity, BTU/ft $\sec ^{\circ} \mathrm{R}$ \\
\hline LHSTF & $\begin{array}{l}\text { Liquid Hydrogen Structural Test Facility, } \\
\text { Dryden Flight Research Facility, } \\
\text { Edwards, CA }\end{array}$ \\
\hline $\mathrm{LH}_{2}$ & liquid hydrogen \\
\hline NIST & $\begin{array}{l}\text { National Institute of Standards and } \\
\text { Technology, Boulder, CO }\end{array}$ \\
\hline $\operatorname{Pr}$ & Prandtl number $=\mu c_{p} / k$ \\
\hline $\mathbf{R a}$ & Rayleigh number $=\mathrm{Gr} \mathrm{Pr}$ \\
\hline $\operatorname{Re}$ & Reynolds number $=u x / \nu$ \\
\hline $\mathrm{S}$ & circumferential surface distance, $\mathrm{ft}$ \\
\hline $\mathrm{T}$ & temperature, ${ }^{\circ} \mathbf{R}$ \\
\hline TAV & transatmospheric vehicle \\
\hline$u$ & characteristic velocity, $\mathrm{ft} / \mathrm{sec}$ \\
\hline$x$ & characteristic length, $\mathrm{ft}$ \\
\hline $\mathrm{Y}$ & vertical distance, $\mathrm{ft}$ \\
\hline$\beta$ & $\begin{array}{l}\text { volumetric thermal expansion coeffi- } \\
\text { cient, } 1 /{ }^{\circ} \mathrm{R}\end{array}$ \\
\hline$\mu$ & dynamic viscosity, lbm sec/ft ${ }^{2}$ \\
\hline$\nu$ & kinematic viscosity, $\mathrm{ft}^{2} / \mathrm{sec}$ \\
\hline $1-D$ & one-dimensional \\
\hline $2-\mathrm{D}$ & two-dimensional \\
\hline \multicolumn{2}{|c|}{ Subscripts } \\
\hline$V$ & vapor \\
\hline$W$ & wall \\
\hline
\end{tabular}

\section{Introduction}

Transatmospheric vehicles (TAVs) such as the National Aerospace Plane will require a fuselage which can withstand high aerodynamic heating while providing an insulation system. This insulation system must reduce the heat load imposed on liquid hydrogen contained within onboard fuel tanks. Material degradation, which occurs at the elevated surface temperatures associated with aerodynamic heating, restricts or disqualifies the use of many standard cryogenic insulating materials, such as closed-cell foams or vacuumjacketed multi-layer insulations. Thermal gradients which develop within the walls of the fuel tank can lead to high thermal stresses that affect tank integrity. Therefore, the development of new insulating systems for cryogenic fuel tanks and the validation of tank in- tegrity over a wide range of flight conditions will require extensive testing.

Tankage systems for TAVs have a significant impact on the overall vehicle design and have been the subject of several experimental test programs. ${ }^{(1-3)}$ These test programs helped to design, fabricate, and obtain experimental validation of liquid hydrogen tankage applicable to vehicles in hypersonic environments. Because of the complex thermal interactions between the cryogenic fuel and the tank structure, the numerical simulation and optimization analysis of tank designs have also been an integral part of experimental test programs. ${ }^{(4,5)}$

Personnel at the NASA Dryden Flight Research Facility in Edwards, California are currently involved in the design of the Liquid Hydrogen Structural Test Facility (LHSTF), to be completed in late 1993. When completed, the LHSTF will be able to test various fullscale and sub-scale flight vehicle components in simultaneous cryogenic and high-temperature environments combined with mechanical loads. The LHSTF design consists of a large test cell for evaluating the performance and integrity of proposed TAV fuel tanks and associated insulation systems. In addition, the LHSTF site layout will provide for future capabilities including an actively cooled panel and turbomachinery test capability, altitude simulation, and full-scale vehicle fuselage and integrated systems tests.

In preparation for cryogenic test operations, personnel from NASA Dryden and PRC Inc. (formerly Planning Research Corporation) have designed the Generic Research Cryogenic Tank (GRCT) as the first test article scheduled for testing in the LHSTF. As a research tank, the GRCT was designed to qualitatively simulate the thermal response of a TAV fuel tank exposed to the environment of hypersonic flight. The GRCT was designed to be a sturdy test article capable of withstanding a variety of operational and research tests.

In studying the GRCT, NASA personnel will gain experience in operating, testing, and analyzing structures in simultaneous cryogenic and high-temperature environments. Operationally, the GRCT will allow NASA personnel to learn how to handle cryogens and the associated equipment required for conducting cryogenic tests. Test operations with the GRCT will help develop and verify instrumentation capable of operating in both cryogenic and high-temperature environments, and help evaluate the thermal performance 
of various insulation systems. To augment analysis efforts, the GRCT will provide test data for refining numerical models developed for simulating the thermal response of cryogenic tanks. Initial tests of the GRCT containing liquid nitrogen will be conducted in the high bay of the NASA Dryden Thermostructures Research Facility with subsequent liquid hydrogen tests conducted in the LHSTF. In addition, the GRCT will be used to perform the LHSTF integrated systems test before testing large and expensive TAV cryogenic fuel tanks.

Numerical models were required to evaluate the thermal performance of the GRCT and to answer various design questions about insulation thickness, purge gas effects, and temperature gradients within the wall of the pressure vessel. To assist in the design and evaluation of the GRCT thermal performance, one- dimensional (1-D) and two-dimensional (2-D) thermal models were created using the Systems Improved Numerical Differencing Analyzer and Fluid Integrator (SINDA'85/FLUINT). ${ }^{(6)}$ The SINDA'85/FLUINT uses a finite-difference solution method for analyzing thermal-fluid systems.

This paper describes the components of the GRCT, the development of the 1-D and 2-D thermal models, and the response of the numerical models to several GRCT liquid hydrogen test scenarios. Transient results for the 1-D and 2-D thermal models are presented with a discussion of the effects the numerical results had on the design of the GRCT.

\section{Overview of the GRCT}

Figure 1 shows a perspective view of the GRCT, suspended below a steel support structure, without

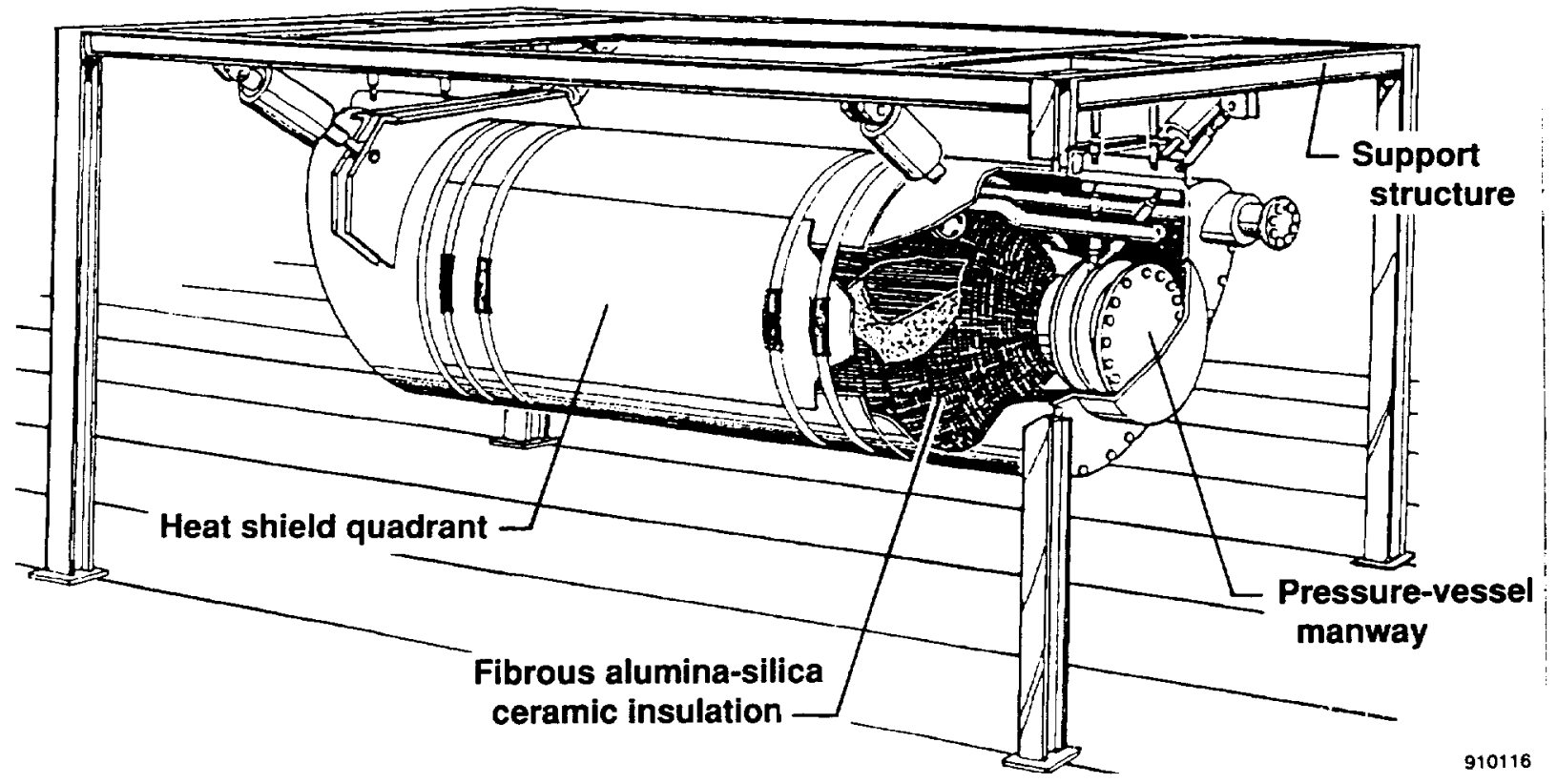

Fig. 1 Perspective view of the Generic Research Cryogenic Tank (GRCT). 
the piping and heat lamps required for testing. Figure 2 shows a cut-away view of the GRCT along the sel. This purge region serves two purposes. First, since some anticipated liquid hydrogen test scenarios

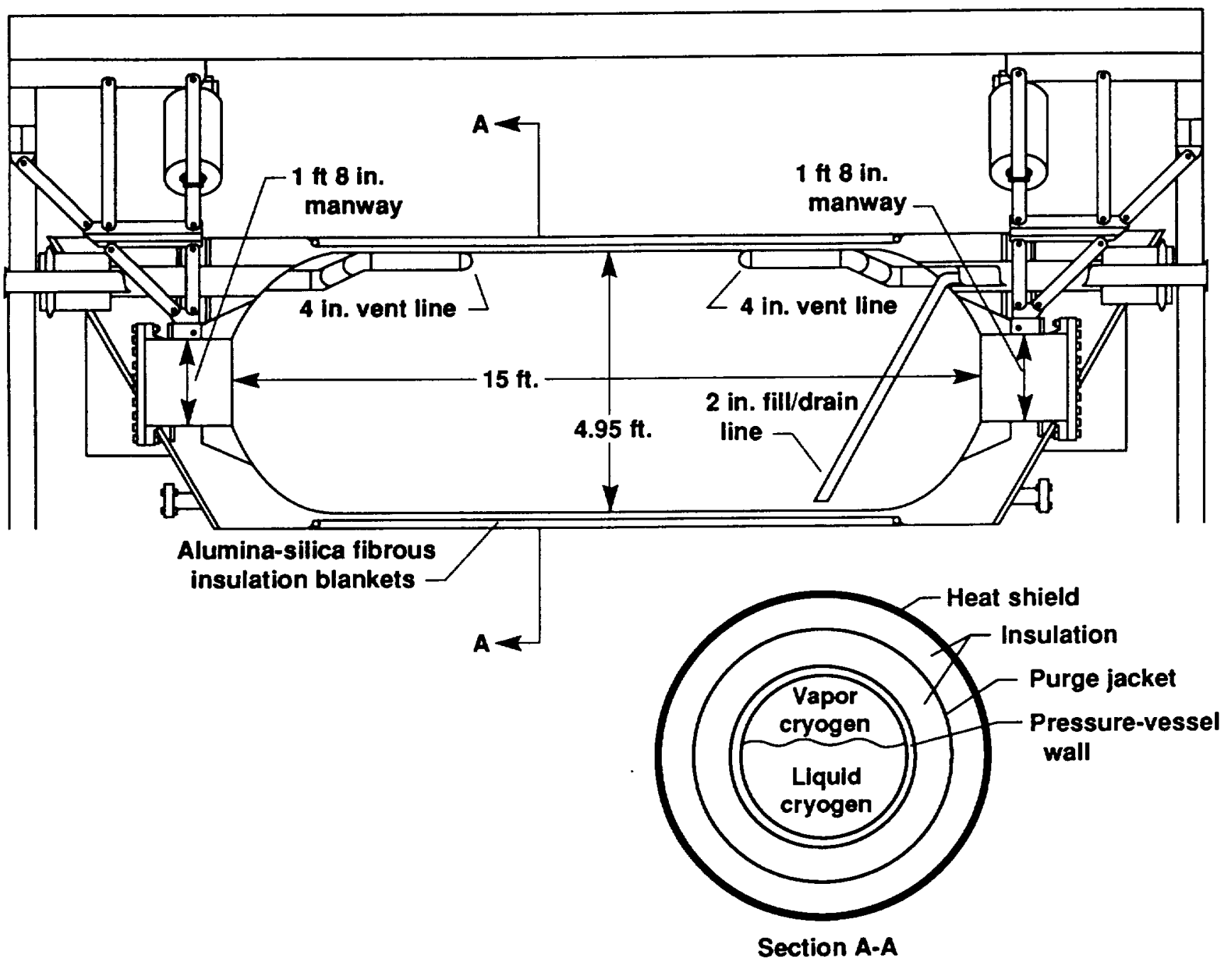

Fig. 2 Cut-away view of the GRCT and a section view of the test section (not to scale).

centerline and a section view through the $10 \mathrm{ft}$ center test section. As shown in Figs. 1 and 2, the GRCT consists of a cylindrical stainless-steel pressure vessel ( 5 - $\mathrm{ft}$ diameter by $15-\mathrm{ft}$ length by $5 / 16$-in. thick) surrounded by 3 in. of fibrous alumina-silica ceramic insulation blankets ( $8 \mathrm{lbm} / \mathrm{ft}^{3}$ density) surrounded by a thin Inconel ${ }^{\text {B }}$ heat shield $(0.030$-in. thick). A purge jacket of 0.005 -in. thick nickel foil is located within the insulation at $1.5 \mathrm{in}$. from the pressure vessel. Purge gas, helium for liquid hydrogen tests and nitrogen for liquid nitrogen tests, will be pumped into the end bell sections of the GRCT and channeled into the inner $1.5 \mathrm{in}$. of insulation next to the pressure ves-

\footnotetext{
(8) Inconel is a registered trademark of Huntington Alloy Products Division, International Nickel Company, Huntington, WV.
}

will be conducted in an air atmosphere within the LHSTF, a helium purge region reduces the possibility of a hydrogen leak forming a combustible mixture with air. Second, the purge region eliminates the liquefaction of air or nitrogen (the two LHSTF test cell atmospheres) within the insulation which degrades insulation performance and creates potential safety and maintenance problems.

Allowing for an adequate ullage (the unfilled portion of a container) for pressure relief, the maximum fill level for the GRCT will be from 85 to 90 percent of the total pressure vessel volume of $267 \mathrm{ft}^{3}$. A filldrain line to the pressure vessel simulates the liquid cryogen outflows required during TAV flight profiles for engine and cooling requirements. The fill-drain 
line has been sized to provide a maximum cryogen outflow rate of $2 \mathrm{lbm} / \mathrm{sec}$. A pressurization line was incorporated in the pressure vessel design to provide tank pressure maintenance during cryogen outflow. Vent lines, with back-pressure regulators, are used to control the pressure within the pressure vessel and allow a maximum pressure of $\mathbf{4 5}$ psia. Instrumentation access is provided for temperature, pressure, and liquid level measurements within the pressure vessel. As a design requirement, the fill-drain, pressurization, vent, and instrumentation penetrations are confined to the hemispherical ends of the GRCT to provide a uniform cylindrical test section clear of penetrations.

During test operations, clamshell quartz lamp heaters will be placed around the suspended GRCT. The quartz lamps will heat the outer heat shields and provide the temperature load on the GRCT. Figure 3 shows the proposed heating profiles to be applied to the fects on the ullage, the high-temperature profile will be applied to the GRCT upper heat shield quadrant (hot-top) while the low-temperature profile (peak temperature of $1260^{\circ} \mathrm{R}$ ) is applied to the lower quadrant. To examine high-temperature effects on the liquid region, the profiles will be reversed (hot-bottom). During nonuniform heating, the side quadrants of the heat shield will follow a heating profile composed of an average of the high- and low-temperature profiles.

\section{Description of the Thermal Models}

The GRCT design provides a test capability with either liquid nitrogen or liquid hydrogen. The thermal models developed to simulate the response of the GRCT also simulate either liquid nitrogen or hydrogen. However, analyzing the GRCT design focused on the thermal response associated with liquid hydrogen

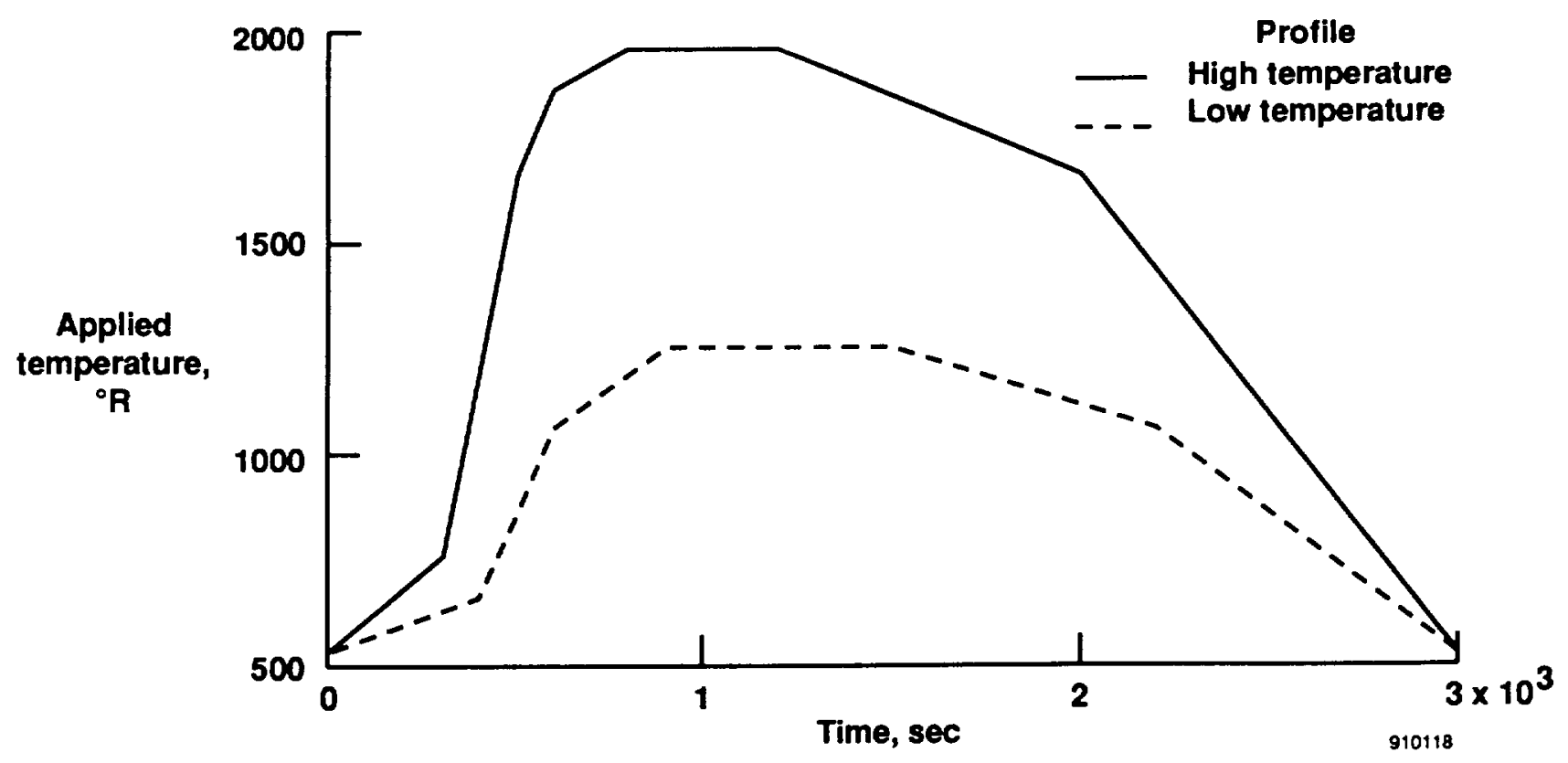

Fig. 3 Proposed heating profiles applied to the heat shields of the GRCT.

heat shields of the GRCT. These temperature profiles represent the temperature loads associated with TAV flight trajectories. A baseline even-heating test case will consist of the high-temperature profile (peak temperature of $1960^{\circ} \mathrm{R}$ ) uniformly applied to the heat shield. To investigate the effects of nonuniform heating associated with TAV ascent and descent flight trajectories, the two heating profiles shown in Fig. 3 will be applied nonuniformly. To examine temperature ef- testing and the results presented are confined to liquid hydrogen test conditions.

\section{One-Dimensional Thermal Model}

The GRCT 1-D thermal model was developed to determine the required insulation thickness and the location of the purge liner. The 1-D model represented a radial section of the GRCT from the liquid hydrogen to the heat shield and accounted for conduction, 
convection, and radiation heat transfer. Figure 4 is a schematic of the node and conductor layout used for ture of hydrogen for 45 psia. The amount of boiloff produced during each time step was calculated by

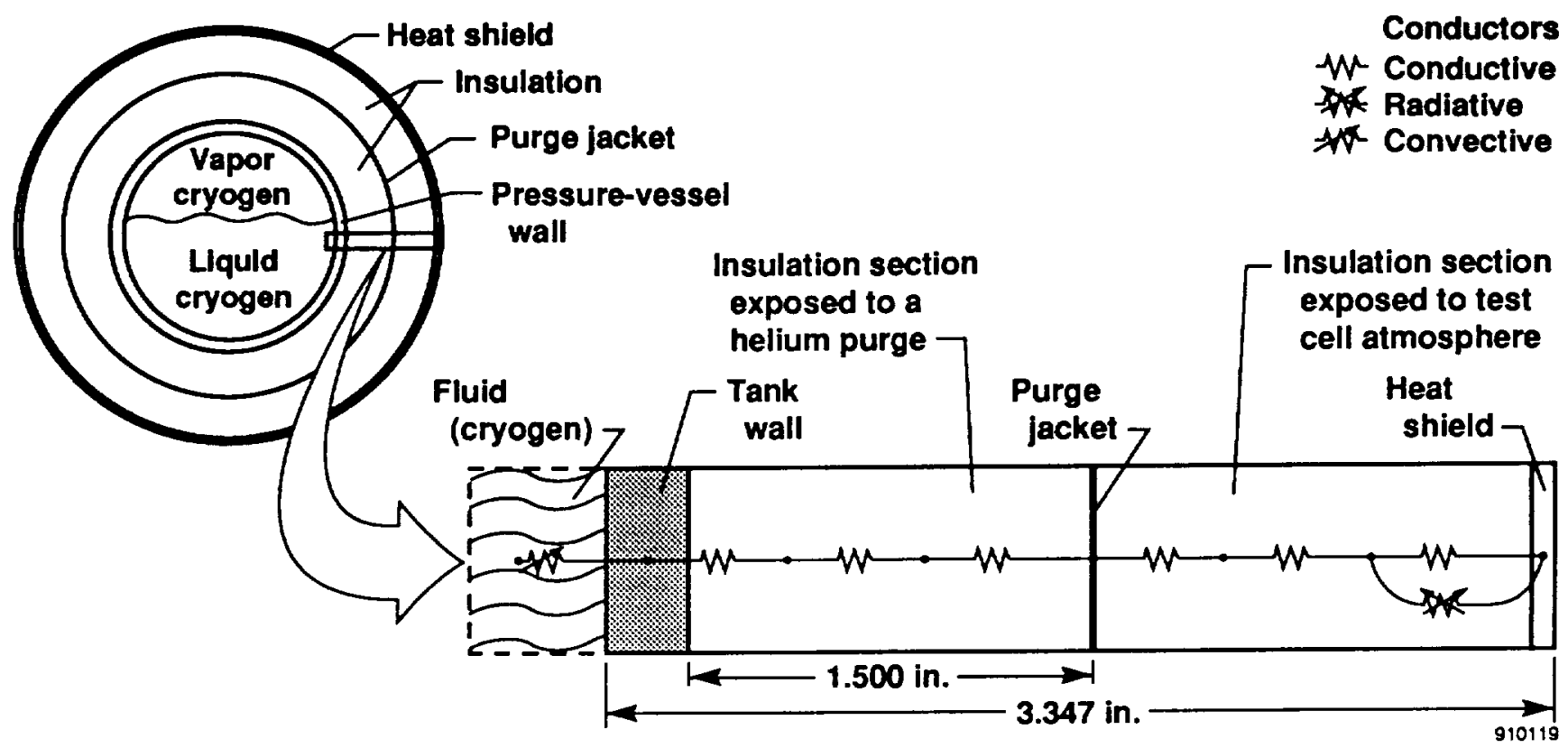

Fig. 4 Representative schematic of the node and conductor layout for the 1-D thermal model.

the 1-D thermal model. A total of 36 nodes, each with a constant $1 \mathrm{ft}^{2}$ area, were used in the model. The thermal conductivity of the Inconel heat shield, insulation, and stainless-steel pressure vessel was tabulated as functions of temperature. ${ }^{(7,8)}$ Heat transfer through the insulation was modeled entirely by conduction, while conduction and radiation heat transfer were included between the heat shield and the outer insulation layer. A constant effective emissivity of 0.53 and a view factor of 1.0 were assumed for the radiation heat transfer between the heat shield and the insulation.

All computational test scenarios were examined assuming a constant tank pressure of 45 psia. Liquid hydrogen was assumed to be in continuous contact with the pressure-vessel wall with nucleate boiling defined as the mode of heat transfer for the wall-to-liquid interface. The heat transfer coefficient between the pressure-vessel wall and the liquid hydrogen was estimated from the corresponding Kutateladze correlation for nucleate pool boiling and tabulated as a function of the temperature difference between the pressure vessel and the liquid cryogen. ${ }^{(9)}$ Nucleate boiling was assumed to produce a well mixed liquid region, which allowed the liquid node to be held at the saturation tempera- dividing the heat transferred into the liquid node by the enthalpy of vaporization for hydrogen (193 BTU/1bm).

A problem with the insulation thermal conductivity was identified during the 1-D thermal modeling work. Insulating materials are often not well characterized for applications involving large temperature gradients. High-temperature conductivity values are often measured using a small imposed temperature gradient, but materials used within the GRCT will be exposed to gradients in excess of $600^{\circ} \mathrm{R}$ per inch. Under these conditions, fiber-to-fiber radiation can contribute to the overall apparent thermal conductivity of the insulation. The impact of purge gas (nitrogen or helium) on the apparent thermal conductivity must also be considered. Gas conduction is the dominant heat transfer mechanism for fibrous insulation systems at atmospheric pressure. ${ }^{(10)}$ Therefore, because helium is more conductive than air, the characteristics of the apparent thermal conductivity for the selected fibrous insulation will change in the presence of a helium purge. A program is currently underway with the National Institute of Standards and Technology (NIST) to measure the apparent conductivity of the GRCT fibrous aluminasilica insulation at high temperature gradients coupled with helium and nitrogen purge gases. The addition 
of the resulting apparent conductivity data from NIST will enhance the prediction capability of the thermal models developed for the GRCT.

The NIST data were not available for this study, hence, the manufacturer's thermal conductivity data for the insulation was used within the GRCT thermal models. However, since the insulation conductivity data were obtained by the manufacturer in an air atmosphere, the effects of a helium purge gas on the insulation thermal conductivity had to be modeled. To estimate the helium purge effects on the fibrous insulation, tabulated data for the thermal conductivity of perlite, a silica powder, for densities from 6 to $9 \mathrm{lbm} / \mathrm{ft}^{3}$ and for various interstitial gases at one atmosphere were examined. ${ }^{(11)}$ These data showed that the ratio of the perlite thermal conductivity containing helium to that containing nitrogen was approximately three for all densities. Therefore, to simulate the effects of a helium purge gas within the GRCT insulation, the manufacturer's thermal conductivity data was multiplied by three within the purge region (inner $1.5 \mathrm{in}$.) and remained unchanged in the outer insulation region (outer 1.5 in.).

\section{The Two-Dimensional Thermal Model}

The 2-D thermal model of the GRCT was created to examine the temperature gradients developed within the pressure-vessel wall, refine the calculation of cryogen boiloff, and characterize the thermal behavior of the ullage. The 2-D model represented a 1-ft wide portion of the GRCT cylindrical test section and modeled the hydrogen liquid and ullage regions. Figure 5 is a schematic of the node and conductor layout used for the 2-D thermal model composed of 413 nodes. Twenty-six circumferential locations were defined between the pressure vessel and the heat shield boundaries. At each circumferential location, 15 nodes were used to model the radial and circumferential heat transfer from the pressure-vessel wall, through the insulation, and to the heat shield. Each node within this region had a cross-sectional area and volume proportional to its radial location. The hydrogen contained in the GRCT was modeled by dividing the pressurevessel cross-sectional area into 12 horizontal sections from top to bottom, with the uppermost horizontal section containing 3 vapor nodes. When the pressure vessel was 85-percent full, the top 5 fluid nodes were vapor and the remaining nodes were defined as liquid (a total of 18 nodes in liquid). Based on results of the
1-D model, only one radial node was defined within the pressure-vessel wall at each circumferential location since the radial temperature gradients were small. The 2-D thermal model assumed a constant tank operating pressure of 45 psia and assumed the liquid hydrogen was well mixed and remained at the prescribed saturated liquid temperature.

The 2-D model simulated the effects of hydrogen boiloff on the ullage, in addition to conduction, convection, and radiation heat transfer. The specific heat of the hydrogen vapor nodes and the boiloff gas were tabulated as a function of temperature. ${ }^{(12)}$ As with the 1-D model, the wall-to-liquid heat transfer coefficient for the liquid hydrogen cases was based on the nucleate pool boiling correlation of Kutateladze however, for stability reasons, the correlation was tabulated as a function of time rather than temperature difference.

Both free and forced convection correlations were considered in modeling the wall-to-vapor heat transfer within the ullage, however, an estimate was made to determine if either was a dominant convection mode or if mixed convection best described the ullage heat transfer. The flow velocity developed by liquid hydrogen boiloff produced laminar-flow forced convection, while the temperature difference between the vapor and the pressure-vessel wall produced free convection. An aid to determine the dominant convective mode of heat transfer was the ratio of the Grashof number to the Reynolds number squared $\left(\mathrm{Gr} / \mathrm{Re}^{2}\right)$ which provides a measure of the ratio of buoyancy forces (free convection) to inertial forces (forced convection). ${ }^{(13)}$ A flow is considered dominated by free convection if $\mathrm{Gr} / \mathrm{Re}^{2} \gg 1$ and dominated by forced convection if $\mathrm{Gr} / \mathrm{Re}^{2} \ll 1$. The liquid hydrogen 85 -percent fill level test case yielded a $\mathrm{Gr} / \mathrm{Re}^{2}$ ratio on the order of $1 \times 10^{5}$ which suggested that the wall-to-vapor heat transfer was dominated by free convection. Determining whether the free convective flow was laminar or turbulent was deduced from the Rayleigh number (Ra), which is a measure of the ratio of the buoyancy forces to the viscous forces. A free convective flow is considered laminar if $\mathrm{Ra}<10^{9}$ and considered turbulent if $\mathrm{Ra}>10^{9}$. The $\mathrm{Ra}$ for the liquid hydrogen 85-percent fill level test case was on the order of $10^{12}$ to $10^{14}$. As a result, the wall-tovapor heat transfer within the ullage was modeled as turbulent-free convection and calculated from the temperature difference between the pressure-vessel wall 


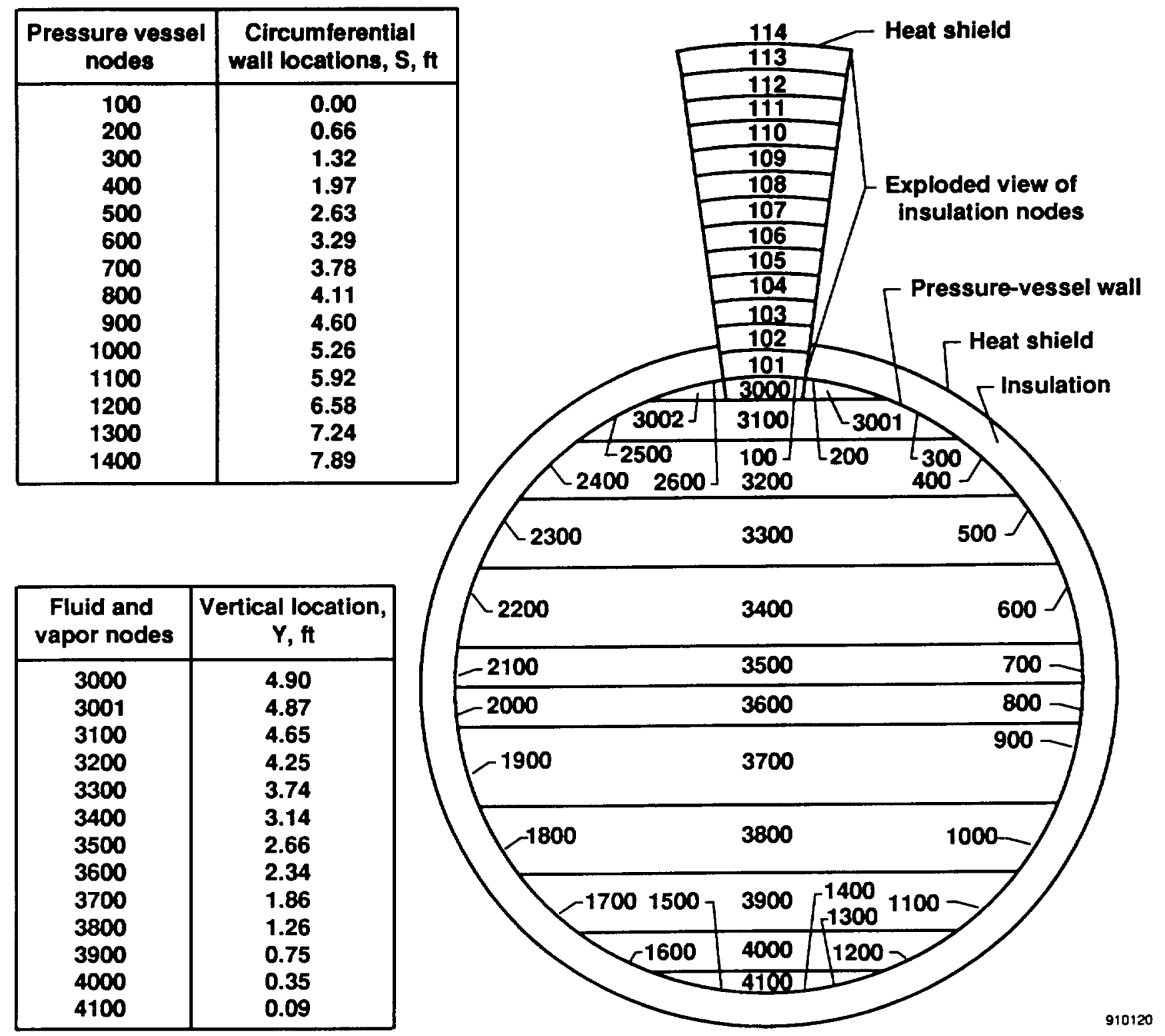

Fig. 5 Representative schematic of the node and conductor layout for the 2-D thermal model.

and the hydrogen vapor. The form of the turbulentfree convection correlation ${ }^{(14)}$ used in the 2-D model is given by

$$
h=0.13 \frac{k}{x}(\operatorname{Gr} \operatorname{Pr})^{1 / 3}
$$

where $k$ and $\operatorname{Pr}$ were the thermal conductivity and Prandtl number of hydrogen, and $x$ was a characteristic length (the pressure vessel diameter of $5 \mathrm{ft}$ ).

Test cases representing a stratified or well mixed ullage condition were examined by modifying the vaporto-vapor heat transfer coefficient within the ullage. To verify the GRCT design under worst case conditions, the ullage vapor-to-vapor heat transfer coefficient was modeled by gaseous conduction (corresponding to heat transfer coefficients of $4 \times 10^{-6}$ to $2 \times 10^{-5} \mathrm{BTU} / \mathrm{ft}^{2}$ $\mathrm{hr}^{\circ} \mathrm{R}$ ) which produced a high degree of ullage stratification. To simulate a well mixed ullage, the vaporto-vapor heat transfer coefficients (based on gaseous conduction) were multiplied by a factor of $1 \times 10^{6}$ to yield heat transfer coefficients on the same order of magnitude as the wall-to-vapor free convection coefficients (approximately 9 to $20 \mathrm{BTU} / \mathrm{ft}^{2} \mathrm{hr}^{\circ} \mathrm{R}$ ).

Table 1 shows the nomenclature used to identify the conditions of the various liquid hydrogen test cases examined using the 2-D thermal model. 
Table 1. Computational test matrix examined with the 2-D thermal model of the GRCT.

\begin{tabular}{|c|c|c|}
\hline \multirow{2}{*}{$\begin{array}{l}\text { Arrangement of the heating profiles } \\
\text { applied to the heat shield quadrants }\end{array}$} & \multicolumn{2}{|c|}{$\begin{array}{c}\text { Test case identification } \\
\text { (Liquid hydrogen } 85 \text {-percent fill level) }\end{array}$} \\
\hline & Stratified ullage & Well mixed ullage \\
\hline $\begin{array}{l}\text { Nonuniform heating } \\
\text { High-temperature profile-top quadrant } \\
\text { Low-temperature profile-bottom quadrant }\end{array}$ & HT85S & HT85M \\
\hline $\begin{array}{l}\text { Uniform heating } \\
\text { High-temperature profile-all quadrants }\end{array}$ & HA85S & HA85M \\
\hline $\begin{array}{l}\text { Nonuniform heating } \\
\text { High-temperature profile-bottom quadrant } \\
\text { Low-temperature profile-top quadrant }\end{array}$ & HB85S & HB85M \\
\hline
\end{tabular}

Each test case identified in Table 1 describes the type of cryogen modeled, the location of the hightemperature profile, the fill level, and the condition of the ullage. For example, the HT85S identification translates to liquid hydrogen within the pressure vessel, the high-temperature profile applied to the top heat shield quadrant, an 85-percent fill level, and a stratified ullage. All of the other test cases in Table 1 follow a similar nomenclature format.

\section{Computational Results}

\section{One-Dimensional Results}

The 1-D thermal model represented the heat transfer associated with the pressure vessel in contact with liquid hydrogen and did not simulate the heat transfer within the ullage of the GRCT. Therefore, all boiloff calculations within the 1-D results section represent an estimate of the total pressure-vessel boiloff rate based on a 100-percent fill level. The boiloff rate for a 100 percent fill level was calculated by multiplying the 1-D model boiloff rate by the total pressure-vessel internal surface area of $236 \mathrm{ft}^{2}$.

\section{Insulation Thickness}

The effect of insulation thickness on the thermal response of the GRCT was examined using the 1-D model. The design criteria for the GRCT required the insulation system to provide a steady-state pressurevessel wall heat flux of approximately $30 \mathrm{BTU} / \mathrm{ft}^{2} \mathrm{hr}$, simulating the ground hold condition of a possible TAV design. In addition, design criteria for the peak wall heat flux required at least an order of magnitude increase from steady-state conditions (to approximately $300 \mathrm{BTU} / \mathrm{ft}^{2} \mathrm{hr}$ ) within the 3000 -sec applied heating period.
Using the manufacturer's thermal conductivity data, Fig. 6 shows the pressure-vessel wall heat flux predicted for liquid hydrogen and insulation thicknesses of 2 to $6 \mathrm{in}$. The wall heat flux associated with 3 in. of insulation produced a steady-state wall flux of $22 \mathrm{BTU} / \mathrm{ft}^{2} \mathrm{hr}$, corresponding to a steady-state boiloff of $27 \mathrm{lbm} / \mathrm{hr}$, and yielded a peak heat flux of $153 \mathrm{BTU} / \mathrm{ft}^{2} \mathrm{hr}$ which equates to a peak boiloff rate of $187 \mathrm{lbm} / \mathrm{hr}$. The 2-in. insulation thickness produced a steady-state wall heat flux of $33 \mathrm{BTU} / \mathrm{ft}^{2} \mathrm{hr}$, however, it produced an excessive peak heat flux and corresponding boiloff rate ( $384 \mathrm{BTU} / \mathrm{ft}^{2} \mathrm{hr}$ and $469 \mathrm{lbm} / \mathrm{hr}$ ) within the 3000-sec heating period. The 4- to 6-in. range of insulation thicknesses yielded low steadystate wall heat fluxes (16 to $11 \mathrm{BTU} / \mathrm{ft}^{2} \mathrm{hr}$ ) and produced virtually no thermal response within the transient heating period. Because of the anticipated increase in wall heat flux associated with using a helium purge, the 2-in. insulation option was eliminated and 3 in. of insulation was selected for the region between the pressure vessel and the heat shield.

\section{Location of the Purge Liner}

At one atmosphere, air liquefies at $142{ }^{\circ} \mathrm{R}$ and any air within the insulation below this temperature liquefies, degrading insulation performance and creating potential safety and maintenance problems. To eliminate the air liquefaction problem, the nickel foil purge jacket was placed within the insulation at 1.5 in. to ensure the insulation temperature outside the jacket remained above $142^{\circ} \mathrm{R}$. The steadystate hold condition for the GRCT (that is, the GRCT filled with liquid cryogen awaiting the start of a test) produced the lowest insulation temperatures corresponding to the highest probability of 


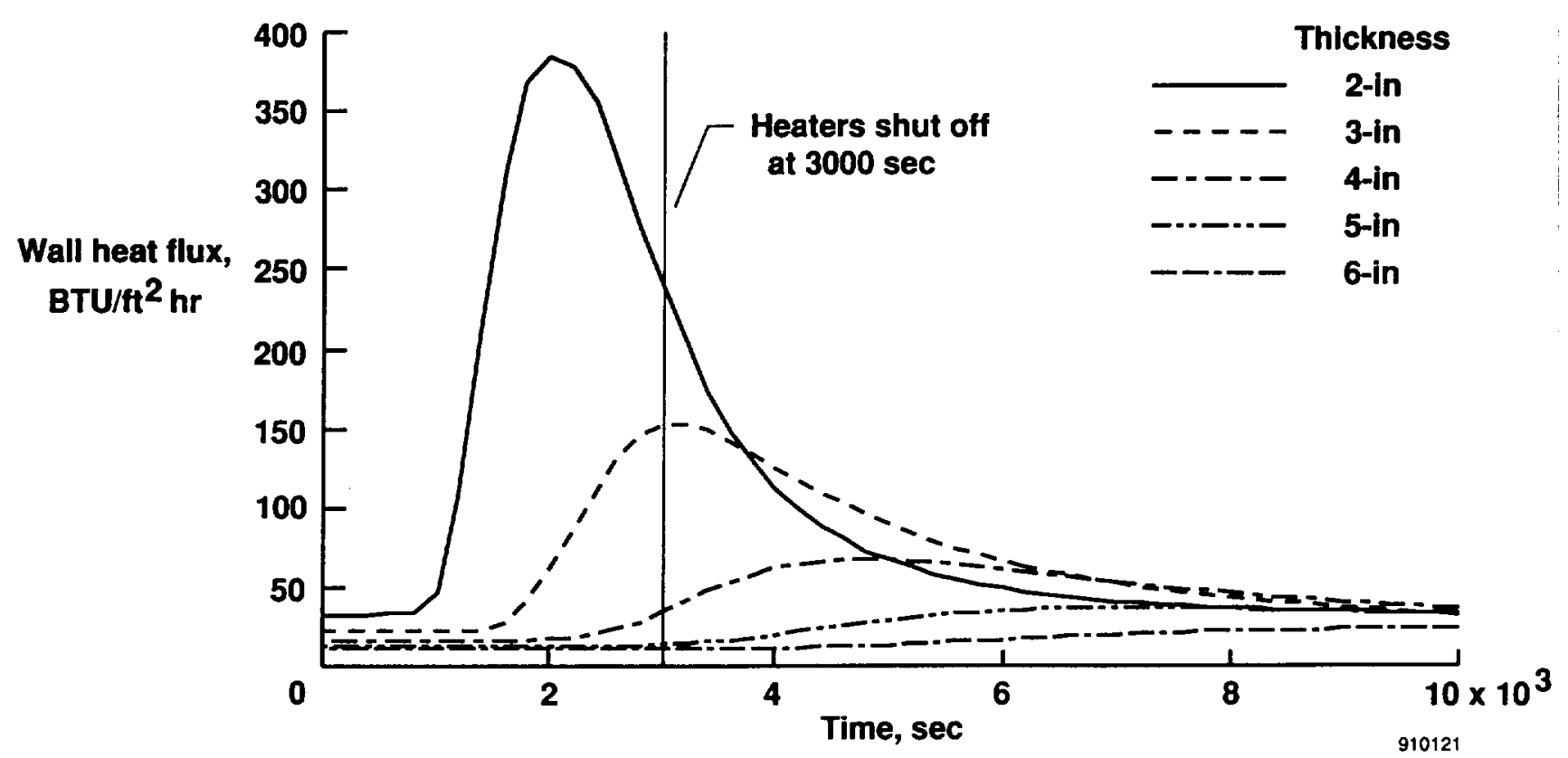

Fig. 6 Pressure vessel wall heat flux as a function of time from the 1-D thermal model with liquid hydrogen and insulation thicknesses from 2 to 6 in.

liquefying air. The liquid hydrogen filled GRCT produced the largest temperature difference between the liquid cryogen and the ambient environment, thereby defining the radial location of the purge jacket.

Figure 7 shows the steady-state and maximum transient temperature distributions through the fibrous insulation with the pressure vessel containing liquid hydrogen. The helium purge was confined to the inner 1.5 in. of insulation next to the pressure vessel. The maximum transient curve shows the peak temperatures that occur within the insulation, while the steadystate curve defines the minimum insulation temperatures associated with the ground hold condition. This

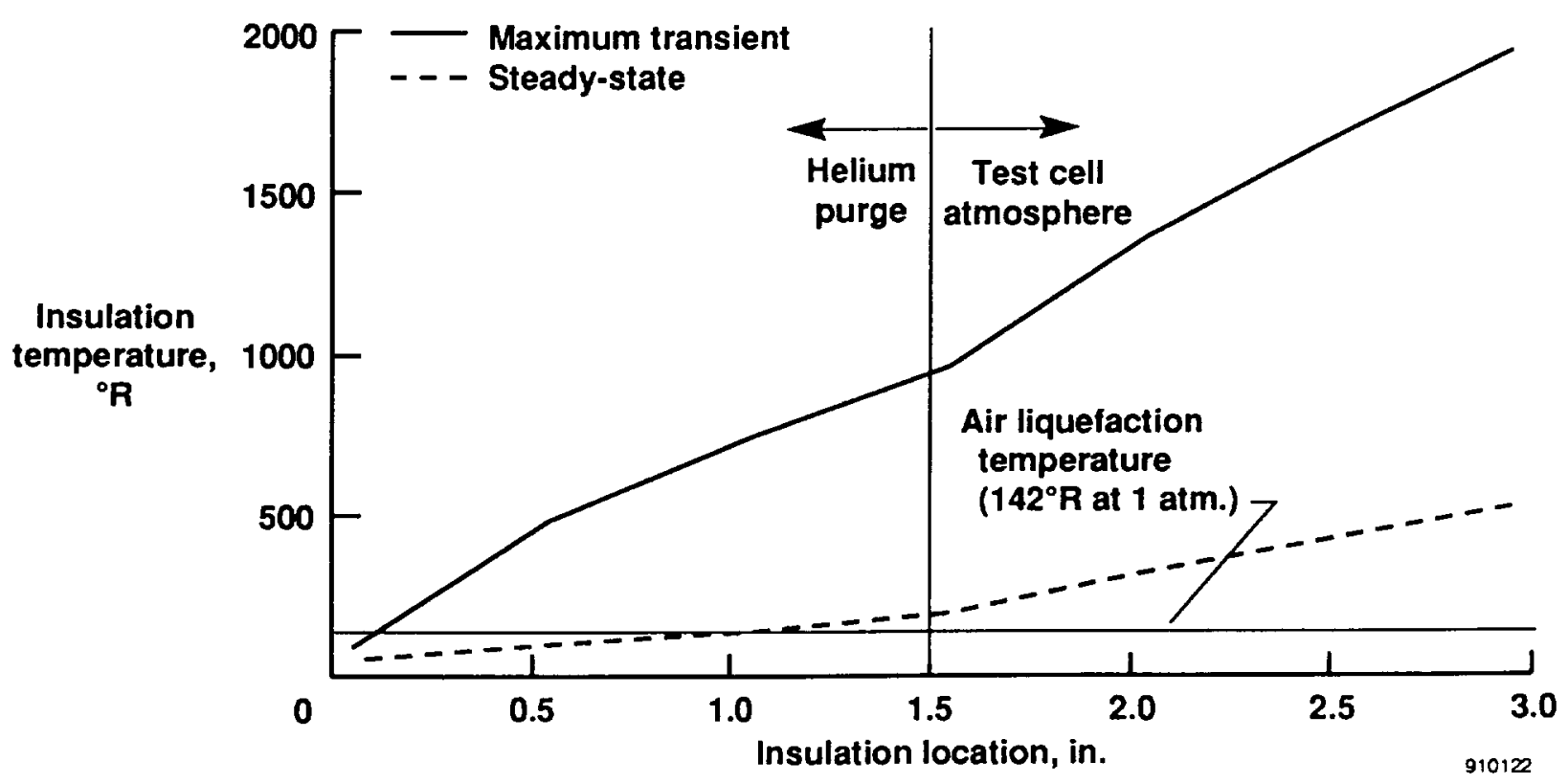

Fig. 7 Steady-state and maximum transient insulation temperature distribution as a function of radial location for a 3-in insulation blanket with a helium purge. 
figure shows that with the purge liner located 1.5 in. from the pressure vessel, the temperature of the unpurged region will remain above the air liquefaction temperature.

\section{Helium Purge Gas Effects}

Figure 8 is a comparison of the pressure-vessel wall heat flux for $3 \mathrm{in}$. of insulation with and without a helium purge. The addition of the helium purge gas

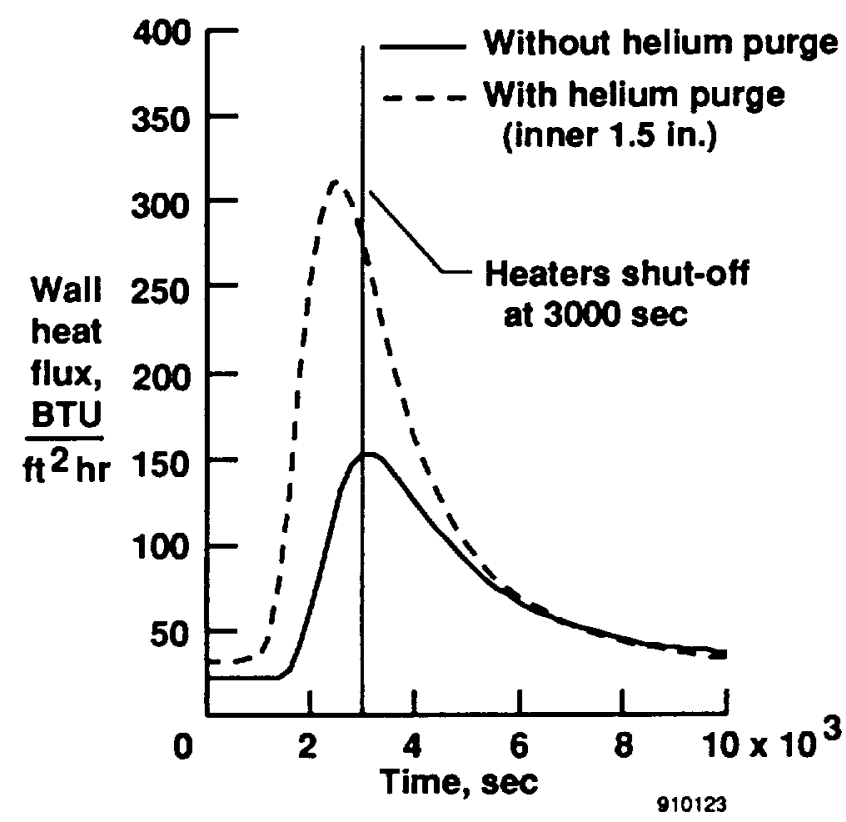

Fig. 8 The 1-D thermal model comparison of pressure vessel wall heat fluxes for a 3-in insulation blanket with and without helium purge as a function of time.

increased the steady-state wall heat flux of the GRCT from $22 \mathrm{BTU} / \mathrm{ft}^{2} \mathrm{hr}$ to $33 \mathrm{BTU} / \mathrm{ft}^{2} \mathrm{hr}$, and increased the steady-state boiloff from $27 \mathrm{lbm} / \mathrm{hr}$ to $40 \mathrm{lbm} / \mathrm{hr}$. The peak transient wall heat flux increased from $153 \mathrm{BTU} / \mathrm{ft}^{2} \mathrm{hr}$ to $312 \mathrm{BTU} / \mathrm{ft}^{2} \mathrm{hr}$ corresponding to an increase in peak transient boiloff from $187 \mathrm{lbm} / \mathrm{hr}$ to $381 \mathrm{lbm} / \mathrm{hr}$. The helium purge gas not only affected the quantitative values of the wall heat flux and boiloff but also the transient behavior of the system. The helium purge gas decreased the thermal resistance of the inner $1.5 \mathrm{in}$. of insulation which caused the pressure vessel to respond more quickly to the imposed thermal environment.

A flexible GRCT design was needed because of uncertainty in the helium purge effects on the insu- lation conductivity. Two methods of controlling the pressure-vessel wall heat flux values have been identified in case the helium purge effects produce higher pressure-vessel wall heat flux values than calculated by the thermal model. First, to reduce the wall heat flux values, the heat shield has been designed to accommodate an additional inch of insulation, yielding a total of 4 in. of insulation if required. Second, the heating profiles may be altered to achieve a desired heat flux at the pressure-vessel wall.

\section{Two-Dimensional Results}

The 2-D thermal model simulated the heat transfer interaction between the ullage and liquid regions of the pressure vessel. Therefore, the total pressure-vessel boiloff rate presented in the 2-D results section for an 85 -percent fill level was calculated by multiplying the 2-D model boiloff rate by the ratio of the total pressurevessel inner surface area $\left(236 \mathrm{ft}^{2}\right)$ to the $2-\mathrm{D}$ model pressure-vessel surface area $\left(15.7 \mathrm{ft}^{2}\right)$. In comparing 1-D and 2-D boiloff rates, the 1-D boiloff rate was multiplied by the total wetted surface area of the pressure vessel for an 85-percent fill level $\left(174 \mathrm{ft}^{2}\right)$.

\section{Liquid Hydrogen Boiloff}

Figure 9 compares the liquid hydrogen boiloff for the 1-D and 2-D thermal models and the HA85S

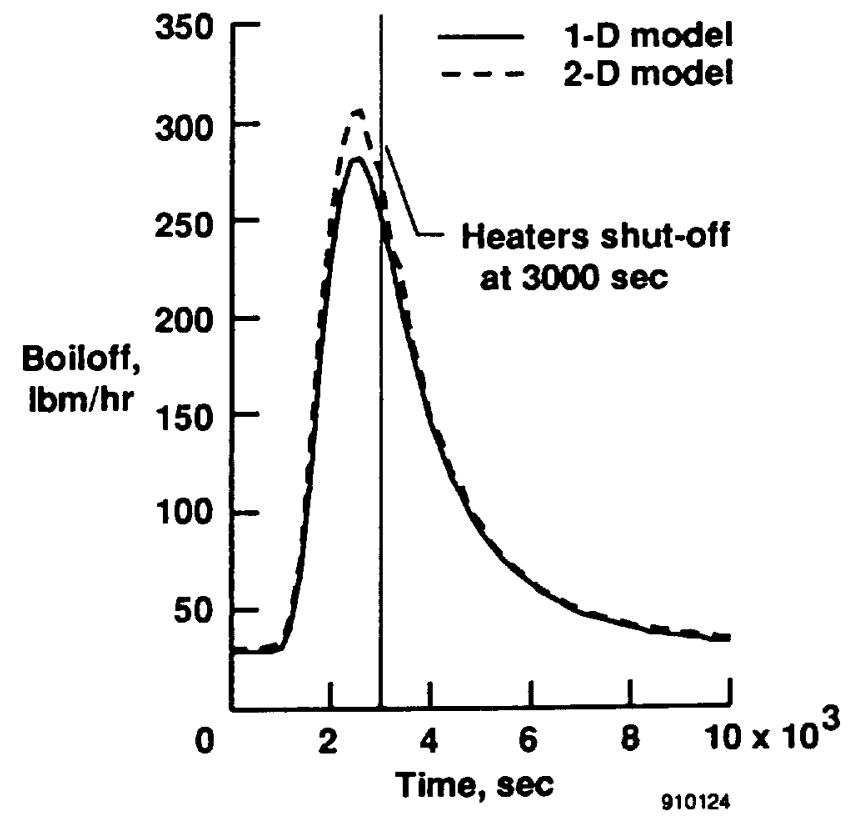

Fig. 9 Comparison of liquid hydrogen boiloff as a function of time for the 1-D and 2-D thermal models and the HA85S test conditions. 
test conditions. Properly scaled for an 85-percent fill level, the 1-D thermal model yielded a transient boiloff rate similar to the 2-D thermal model. For the HA85S test case, the 2-D thermal model calculated a steadystate boiloff of $32 \mathrm{lbm} / \mathrm{hr}$ and a peak boiloff of 305 $\mathrm{lbm} / \mathrm{hr}$, compared with $30 \mathrm{lbm} / \mathrm{hr}$ and $281 \mathrm{lbm} / \mathrm{hr}$ for the 1-D model. Since the additional heat transfer between the ullage and liquid regions was included, the 2-D thermal model provided a more realistic estimate of the transient hydrogen boiloff.

Figure 10 shows a comparison of the liquid hydrogen boiloff as a function of time for the HT85S, HA85S, and HB85S test cases. This figure demon- duced boiloff. With the high-temperature profile in the top quadrant, a lower boiloff was produced because the hydrogen vapor simply absorbed the heat and increased in temperature.

\section{Pressure-Vessel Wall Temperatures}

The maximum wall temperature for the 6 test cases at the 85-percent fill level was determined by examining the transient behavior of the pressure-vessel wall temperature in the ullage. Figure 11 shows the pressure-vessel wall temperature as a function of time for the HT85S test case and for computational nodes 100,400 , and 500 . The peak wall temperature of

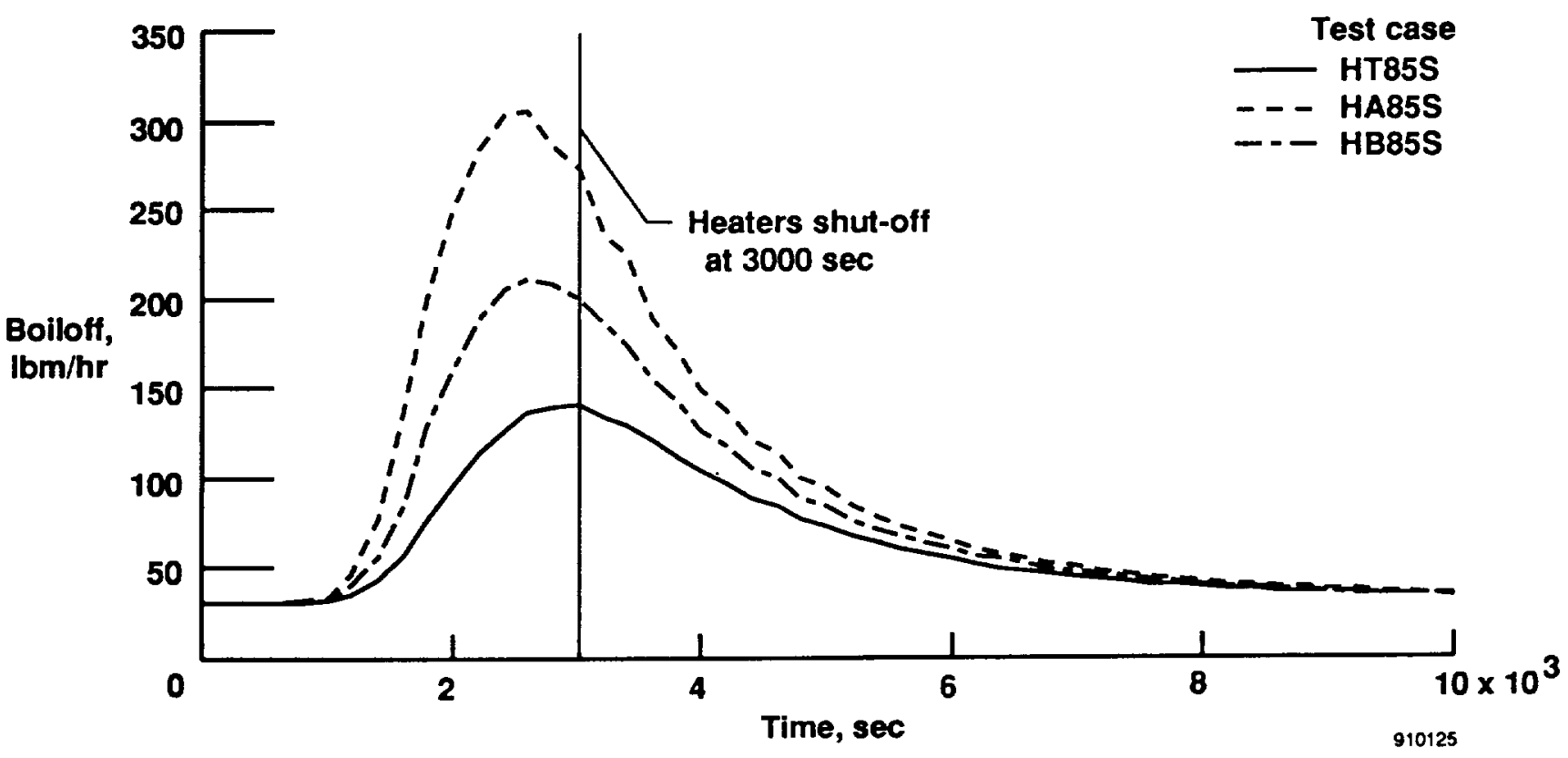

Fig. 10 Comparison of liquid hydrogen boiloff as a function of time for different applied temperature profile arrangements with the 2-D thermal model.

strates the effect the high-temperature profile location had on the cryogen boiloff rate. The highest liquid hydrogen boiloff rate occurred when the high-temperature profile was applied to all heat shield quadrants which yielded the maximum wetted surface area in contact with high wall heat fluxes. For the nonuniformly applied heating profiles, HB85S yielded a higher boiloff than HT85S. With the hightemperature profile on the bottom quadrant, the liquid hydrogen readily absorbed the wall heat flux and pro- $198^{\circ} \mathrm{R}$ occurred at the highest point in the pressure vessel (node 100) at $3600 \mathrm{sec}$. However, the peak temperatures for each node within the pressure-vessel wall did not all occur at the same time. For example, the peak temperature of node $400,75^{\circ} \mathrm{R}$, occurred at $2800 \mathrm{sec}$. This time difference for the peak wall temperatures was caused by the geometric arrangement of the vapor nodes and the resulting boiloff mass distribution. 


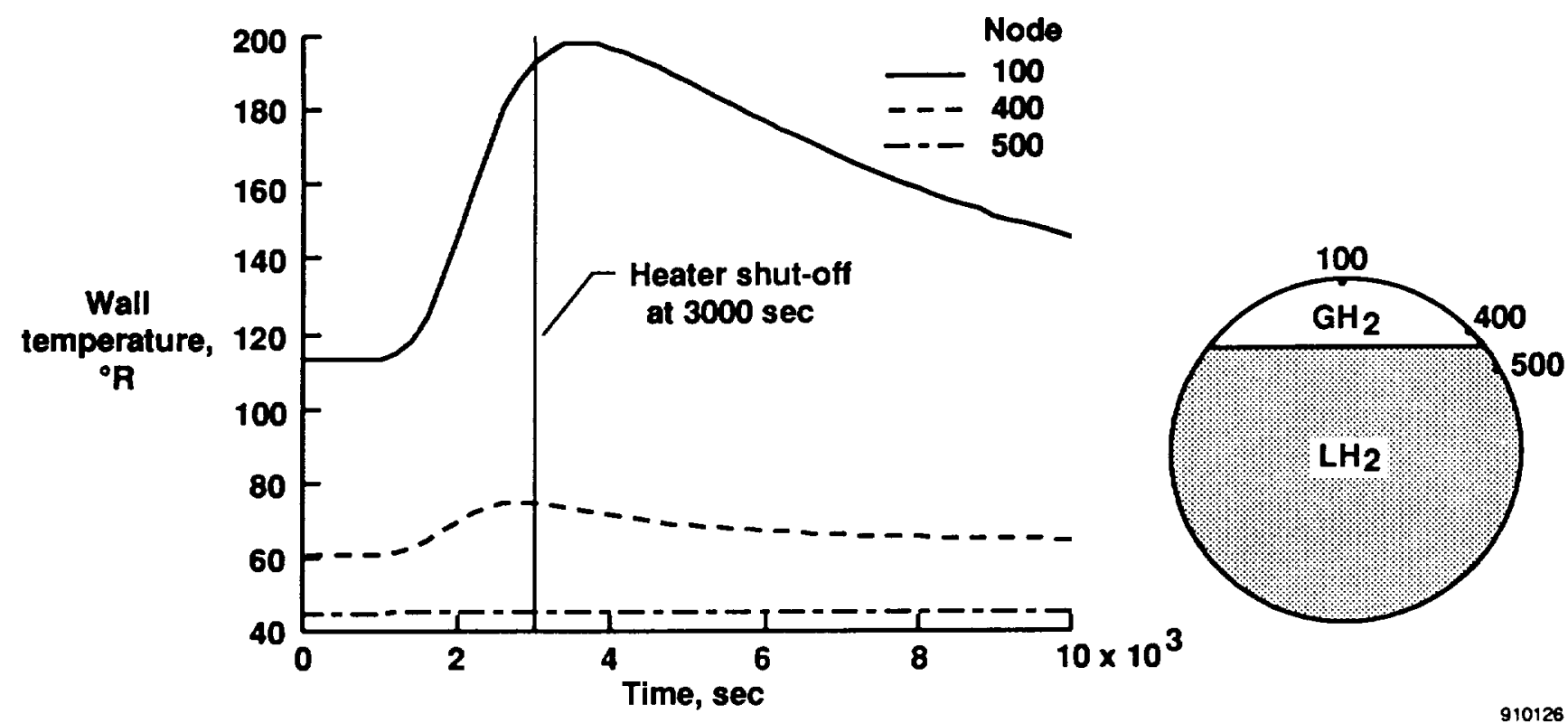

Fig. 11 Pressure vessel wall temperatures as a function of time for the HT85S test case and computational nodes 100,400 , and 500 with the 2-D thermal model.

The HT85S test case (hot-top profile) yielded the peak pressure-vessel wall temperature because the high-temperature profile on the top heat shield quadrant was combined with the lowest boiloff rate (see Fig. 10). Figure 12 shows the transient temperature of node 100 for the 3 locations of the applied high- temperature profile. As shown in Fig. 12, concentrating the high-temperature profile on the top heat shield quadrant yields the lowest boiloff rate, resulting in less cooling available for the wall and ullage regions, which yielded the highest wall temperatures. Conversely, concentrating the high-temperature profile on

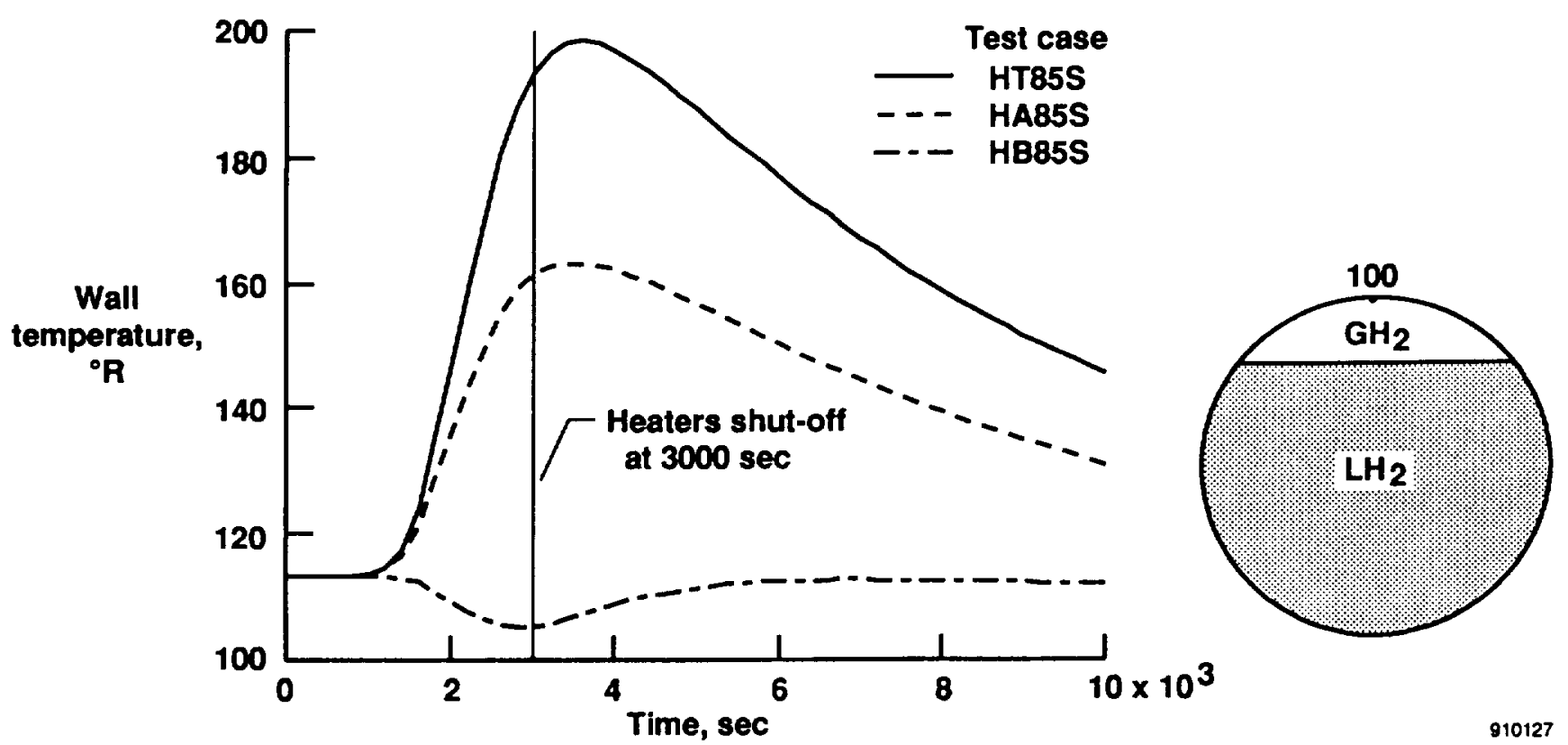

Fig. 12 Pressure vessel wall temperature for node 100 as a function of time for different applied temperature profile arrangements with the 2-D thermal model. 
the bottom heat shield quadrant yielded a moderate boiloff rate, which coupled with the low-temperature profile in the ullage, produced lower overall wall temperatures.

The liquid hydrogen acted as a thermal sink which maintained the wetted pressure-vessel wall temperatures slightly above the saturation temperature of the hydrogen for all of the applied temperature profile arrangements examined. The magnitude of the wallto-liquid heat transfer coefficient for liquid hydrogen did not substantially affect the value of the wetted pressure-vessel wall temperatures.

While examining the ullage heat transfer, various constant values for the wall-to-vapor convective heat transfer coefficient (from 0.5 to $100 \mathrm{BTU} / \mathrm{ft}^{2} \mathrm{hr}{ }^{\circ} \mathrm{R}$ ) were considered. This sensitivity analysis showed that the wall-to-vapor heat transfer coefficient had a minor effect on the pressure-vessel wall and fluid temperatures. Conversely, the magnitude of the vapor-to-vapor heat transfer coefficient (affecting the degree of mixing) greatly influenced the resulting pressure-vessel wall and fluid temperatures. Of all the modes of heat transfer occurring within the pressure vessel, the condition of the ullage vapor (well mixed or stratified) had the most pronounced effect on the pressure-vessel wall temperatures. A stratified ullage yielded higher pressurevessel wall temperatures and circumferential temperature gradients while a well mixed ullage yielded lower wall temperatures and circumferential temperature gradients.

Figure 13 shows the pressure-vessel wall temperature distribution for the HT85S and the HT85M test cases. For the HT85S test case, the pressure-vessel wall temperatures are shown at $0 \mathrm{sec}$ (steady-state) and at $3600 \mathrm{sec}$ (peak temperature). The pressurevessel wall temperatures decreased circumferentially from $\mathrm{S}=0 \mathrm{ft}$ (node 100 , top of the pressure vessel) to $S=2.6 \mathrm{ft}$ (node 500 ) with the heat flowing from the hot upper wall region to the cold wall region in contact with the liquid hydrogen. Figure 13 also provides an estimate of the circumferential temperature gradients that exist within the pressurevessel wall. Comparing the temperature distributions for the HT85S and HB85M test cases shows the decrease in the pressure-vessel wall temperatures and temperature gradients when the ullage was well mixed.

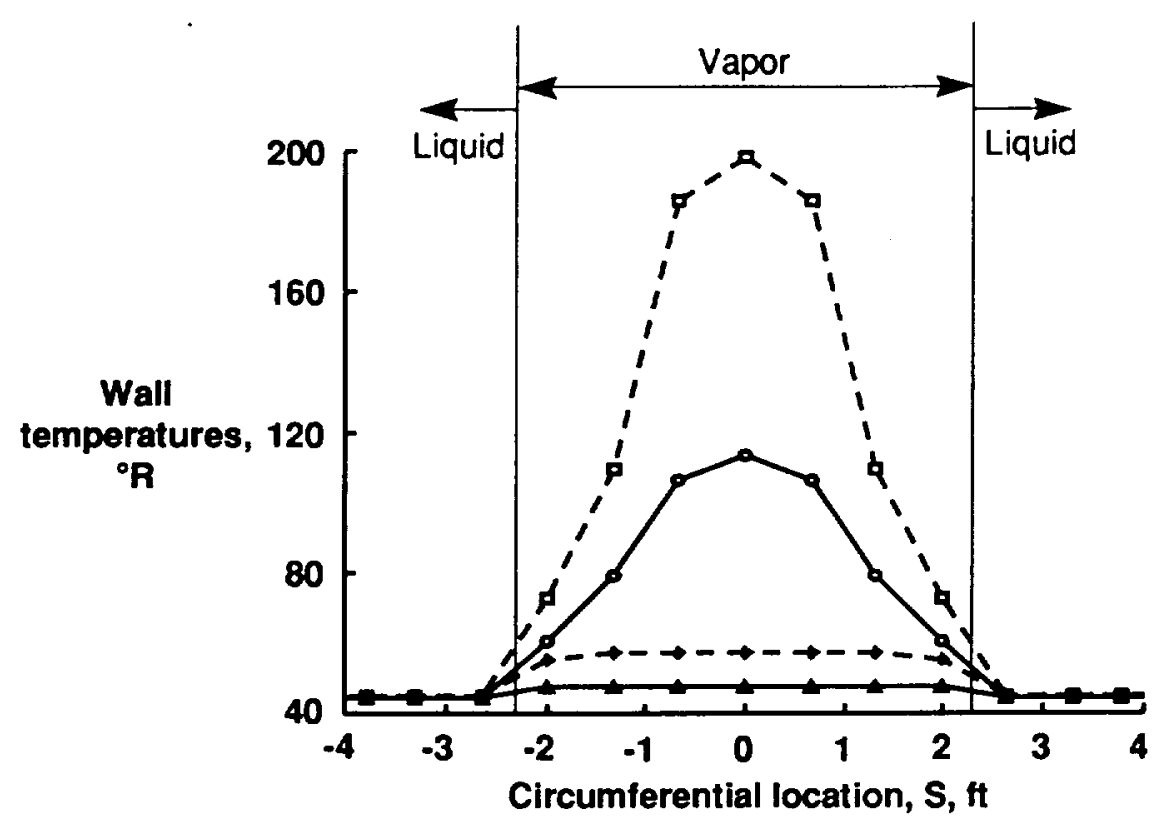

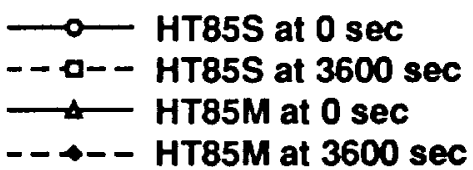

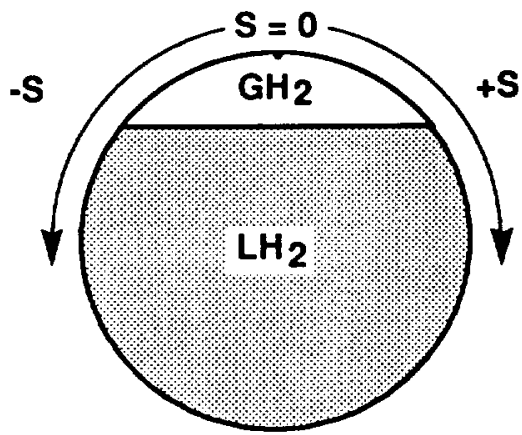

910128

Fig. 13 Steady-state and peak pressure vessel wall temperatures as a function of circumferential location for stratified and mixed ullage conditions with the 2-D thermal model. 


\section{Vapor Temperatures}

Figure 14 shows the vertical temperature distribution of the fluid and vapor nodes at selected times for the HT85S and HT85M test cases. function of the location of the applied heating profiles. The heating profiles influenced the amount of cryogen boiloff which then influenced the vapor temperatures and the corresponding wall temperatures.

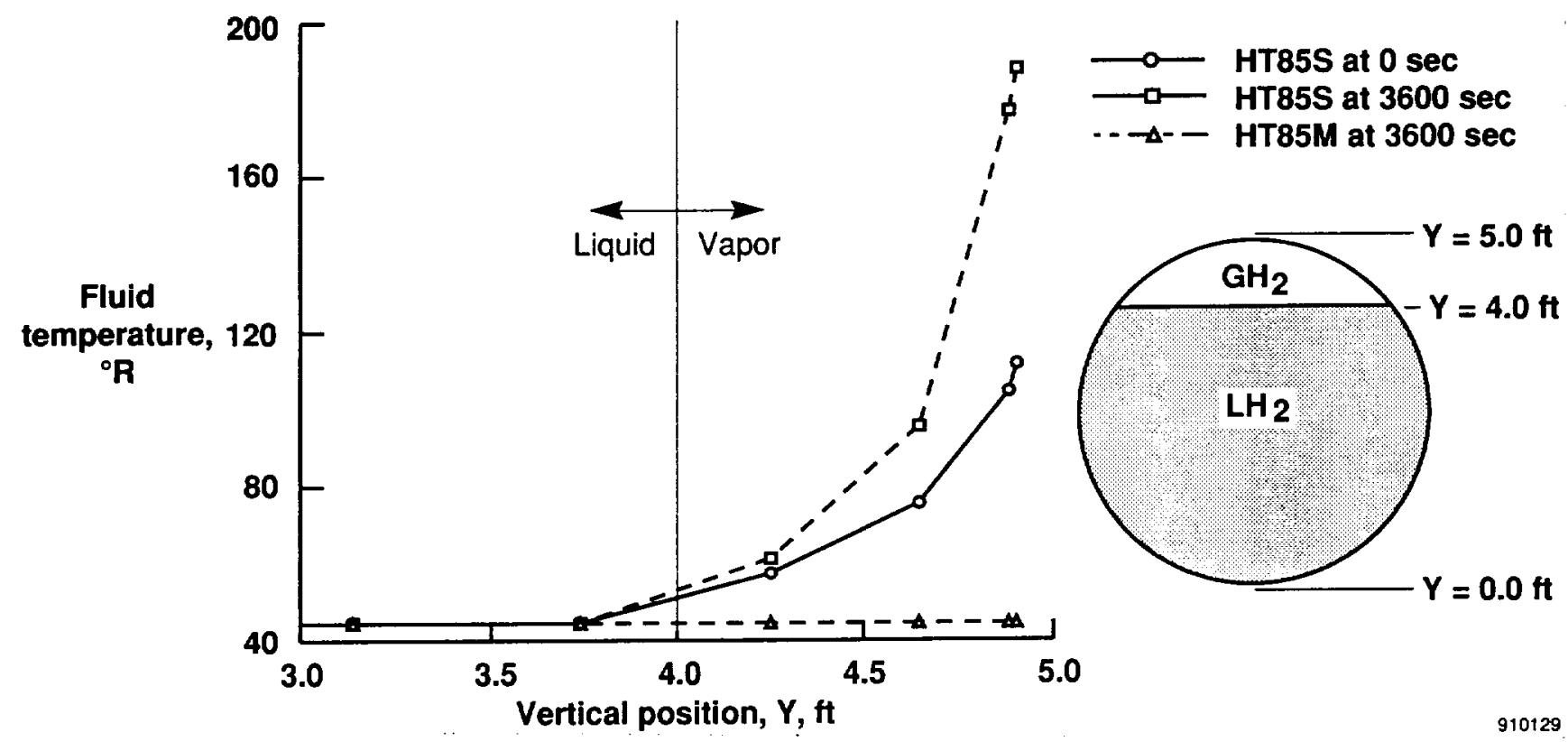

Fig. 14 Liquid and vapor temperatures as a function of vertical position for a stratified and well mixed ullage condition with the 2-D thermal model.

Node 3000 (the top vapor node) reached a peak vapor temperature of $188^{\circ} \mathrm{R}$ at $3600 \mathrm{sec}$, which was $10^{\circ} \mathrm{R}$ cooler than the adjacent wall nodes (see Fig. 11). The temperature gradient associated with the stratified ullage and its change over time is readily apparent in Fig. 14. For a well mixed ullage condition there was virtually no temperature gradient through the vapor region as shown in Fig. 14. The time dependence of the fluid and vapor node temperatures was qualitatively similar to the time dependence of the wall temperatures shown in Figs. 11 and 12.

\section{Pressure Vessel Circumferential Temperature Gradients}

The circumferential temperature gradients developed within the pressure-vessel wall were a strong
The 2-D thermal model was used to examine the peak thermal gradients developed within the pressure-vessel wall for the 85-percent fill level and determine if they were below the design criteria of $112^{\circ} \mathrm{R} / \mathrm{ft}$ prescribed by the structural analysis done by PRC personnel.

Table 2 shows the peak and average circumferential temperature gradients developed within the pressurevessel wall for the different applied heating profiles with stratified and well mixed ullages. The circumferentially averaged temperature gradients were calculated from the pressure-vessel temperature gradients in contact with the ullage at the time the peak gradients occurred (typically 2500 to $5000 \mathrm{sec}$ ). 
Table 2. Peak and average circumferential temperature gradients within the pressure-vessel wall for stratified and well mixed ullages.

\begin{tabular}{|c|c|c|}
\hline \multirow[t]{2}{*}{ Test cases } & \multicolumn{2}{|c|}{$\begin{array}{l}\text { Pressure vessel circumferential } \\
\text { temperature gradients }\left({ }^{\circ} \mathrm{R} / \mathrm{ft}\right)\end{array}$} \\
\hline & Peak & Average \\
\hline \multicolumn{3}{|c|}{ Stratified ullage } \\
\hline HT85S & 116.1 & 58.2 \\
\hline HA85S & 99.9 & 44.8 \\
\hline HB85S & 54.3 & 25.4 \\
\hline \multicolumn{3}{|c|}{ Well mixed ullage } \\
\hline HT85M & 21.0 & 6.6 \\
\hline HA85M & 25.4 & 6.4 \\
\hline HB85M & 13.0 & 3.2 \\
\hline
\end{tabular}

The peak gradient always occurred as a spike that was significantly larger than the rest of the gradients in the ullage. These temperature gradient spikes were the result of several simplifying assumptions built into the 2-D model, including the degree of vapor-tovapor coupling and the distribution of boiloff vapor (for cooling) available to each tank wall node. Circumferentially averaging the ullage temperature gradients reduced the effects of the simplifying model assumptions. Therefore, the averaged values were considered to be more appropriate for design assessment. The average temperature gradients for the stratified ullage case were considerably less than the design criteria. A well mixed ullage yielded average temperature gradients which were considerably lower than for a stratified ullage and were well below the design criteria.

\section{Pressure-Vessel Wall Heat Flux}

Table 3 shows the peak and average pressure-vessel wall heat fluxes with liquid hydrogen for stratified and well mixed ullages. The average wall heat fluxes were calculated from the nodes in contact with liquid or vapor at the time the corresponding peak wall heat fluxes occurred.

Table 3. Peak and average pressure-vessel wall heat fluxes with liquid hydrogen for stratified and well mixed ullages.

\begin{tabular}{|c|c|c|c|c|}
\hline \multirow[t]{2}{*}{ Test cases } & \multicolumn{2}{|c|}{$\begin{array}{l}\text { Wall-to-vapor heat fluxes } \\
\left(\mathrm{BTU} / \mathrm{ft}^{2} \mathrm{hr}\right)\end{array}$} & \multicolumn{2}{|c|}{$\begin{array}{l}\text { Wall-to-liquid heat fluxes } \\
\left(\mathrm{BTU} / \mathrm{ft}^{2} \mathrm{hr}\right)\end{array}$} \\
\hline & Peak & Average & Peak & Average \\
\hline \multicolumn{5}{|c|}{$\overline{\text { Stratified ullage }}$} \\
\hline HT85S & 348.9 & 241.9 & 208.0 & 164.5 \\
\hline HA85S & 378.2 & 309.3 & 351.4 & 342.6 \\
\hline HB85S & 140.7 & 112.5 & 341.3 & 244.0 \\
\hline \multicolumn{5}{|c|}{ Well mixed ullage } \\
\hline HT85M & 340.6 & 318.5 & 200.2 & 163.5 \\
\hline HA85M & 342.2 & 340.7 & 350.7 & 347.0 \\
\hline HB85M & 138.6 & 114.3 & 343.9 & 236.6 \\
\hline
\end{tabular}


The location and magnitude of the peak wall heat flux within the ullage depended on several factors, including the applied high-temperature profile location and the geometric arrangement of the vapor nodes affecting boiloff mass distribution. Averaging the ullage temperature gradients reduced the effects of the simplifying model assumptions. Consequently, the average wall-to-vapor heat flux provided a more realistic indication of the expected wall heat flux. For the hot-top and even heating test cases more heat was transferred into the ullage than for the hot-bottom test cases. Ullage mixing increased the wall-to-vapor heat flux for the hot-top and even heating cases, but had no effect on the hot-bottom cases.

The magnitude of the peak wall-to-liquid heat flux was not dependent on the arrangement of the liquid nodes, but the location of the peak wall-to-liquid heat flux depended on the location of the applied hightemperature profile. For the hot-top and even heating cases, the peak heat flux occurred at the top wall node in contact with the liquid cryogen (node 500 ) because of the additional heat transferred from the ullage. For the hot-bottom heating cases, the peak wall-to-liquid heat fluxes occurred at the bottom of the pressure vessel. The condition of the ullage, whether stratified or well mixed, did not affect the wall-to-liquid heat fluxes within the pressure vessel.

\section{Concluding Remarks}

The one-dimensional and two-dimensional thermal models successfully analyzed the thermal behavior of the Generic Research Cryogenic Tank for several test cases. The insulation thickness around the pressure vessel was sized at 3 in. to provide a steady-state heat flux of $33 \mathrm{BTU} / \mathrm{ft}^{2} \mathrm{hr}$ and produced a peak transient heat flux of $312 \mathrm{BTU} / \mathrm{ft}^{2} \mathrm{hr}$ which occurred within the 3000 -sec heating period. The purge jacket was located $1.5 \mathrm{in}$. within the insulation to eliminate the liquefaction of air which would degrade insulation performance. Large temperature gradients within the wall of the pressure vessel could lead to large thermal stresses, but the average circumferential temperature gradients of the test cases examined were well below the allowable design value of $112^{\circ} \mathrm{R} / \mathrm{ft}$. Refining the cryogen boiloff calculation and subsequently the heat flux into the cryogen defined the thermal performance of the Generic Research Cryogenic Tank more accurately. Mixing in the ullage lowered vapor temperatures by as much as $140^{\circ} \mathrm{R}$ and had a much greater effect on thermal behavior of the ullage than either heating profile location or wall-to-vapor heat transfer characteristics.

The thermal analysis identified several characteristics that affected the thermal behavior of the Generic Research Cryogenic Tank. The characteristics of ullage mixing, the location of applied high-temperatures, and the helium-insulation apparent thermal conductivity all influenced the behavior of the Generic Research Cryogenic Tank. Improvement of subsequent thermal simulations will be the focus of the thermal conductivity tests at the National Institute of Science and Technology and much of the future testing with the Generic Research Cryogenic Tank.

\section{References}

${ }^{1}$ Heathman, John H., "Hydrogen Tankage For Hypersonic Cruise Vehicles - Phase I," Technical Report AFFDL-TR-65-230, Aug. 1966.

${ }^{2}$ Heathman, John H., "Hydrogen Tankage Application To Manned Aerospace Systems Phases II \& III," Technical Report AFFDL-TR-65-75, Volumes I and III, Apr. 1968.

${ }^{3}$ Urie, David M. and Roug, George P., "Zero Length Launch Trans Atmospheric Vehicle (ZEL TAV) Structural Technology Validation Program - Final Report," U.S.A.F. Contract F18600-86-C-4000, Lockheed Aeronautical Systems Co., July 1988.

${ }^{4} \mathrm{Hardy}$, Terry L. and Tomsik, Thomas M., Prediction of the Ullage Gas Thermal Stratification in a NASP Vehicle Propellant Tank Experimental Simulation Using FLOW-3D, NASA TM-103217, 1990.

${ }^{5}$ Teare, D. and Kubik, D., "Integrated Cryo-Tank Thermodynamic Analysis Method," AIAA-90-5214, AIAA Second International Aerospace Planes Conference, Orlando, Fl., Oct. 1990.

${ }^{6}$ Cullimore, B.A., Goble, R.G., Jensen, C.L., and Ring, S.G., "SINDA'85/FLUINT Systems Improved Numerical Differencing Analyzer and Fluid Integrator Version 2.2," Cosmic Program \#MSC-21528, NAS917448, Aug. 1986.

7 "Military Standardization Handbook - Metallic Materials and Elements For Aerospace Vehicle Structures," Volumes 1 and 2, MIL-HDBK-5B, Sept. 1971. 


\begin{tabular}{|c|c|c|c|c|}
\hline 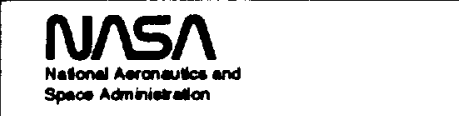 & \multicolumn{4}{|c|}{ Report Documentation Page } \\
\hline $\begin{array}{l}\text { 1. Report No. } \\
\text { NASA CR-186012 }\end{array}$ & \multicolumn{2}{|c|}{ 2. Government Accession No. } & \multicolumn{2}{|c|}{ 3. Recipient's Catalog No. } \\
\hline \multicolumn{3}{|c|}{$\begin{array}{l}\text { 4. Title and Subtitle } \\
\text { Thermal Modeling and Analysis of a Cryogenic Tank Design } \\
\text { Exposed to Extreme Heating Profiles }\end{array}$} & \multicolumn{2}{|l|}{$\begin{array}{l}\text { 5. Report Date } \\
\text { June } 1991\end{array}$} \\
\hline \multirow{2}{*}{\multicolumn{3}{|c|}{$\begin{array}{l}\text { 7. Author(s) } \\
\text { Craig A. Stephens and Gregory J. Hanna }\end{array}$}} & \multicolumn{2}{|c|}{$\begin{array}{l}\text { 8. Performing Organization Report No. } \\
\text { H- } 1720\end{array}$} \\
\hline & & & \multicolumn{2}{|c|}{$\begin{array}{l}\text { 10. Work Unit No. } \\
\text { RTOP 505-63-40 }\end{array}$} \\
\hline \multirow{2}{*}{\multicolumn{3}{|c|}{$\begin{array}{l}\text { 9. Performing Organization Name and Address } \\
\text { NASA Dryden Flight Research Facility } \\
\text { P.O. Box } 273 \\
\text { Edwards, California } 93523-0273\end{array}$}} & \multicolumn{2}{|c|}{$\begin{array}{l}\text { 11. Contract or Grant No. } \\
\text { NAS 2-12722 }\end{array}$} \\
\hline & & & \multicolumn{2}{|c|}{$\begin{array}{l}\text { 13. Type of Report and Period Covered } \\
\text { Contractor Report }\end{array}$} \\
\hline \multicolumn{3}{|c|}{$\begin{array}{l}\text { 12. Sponsoring Agency Name and Address } \\
\text { National Aeronautics and Space Administration } \\
\text { Washington, DC } 20546-3191\end{array}$} & \multicolumn{2}{|c|}{ 14. Sponsoring Agency Code } \\
\hline \multicolumn{5}{|c|}{$\begin{array}{l}\text { NASA Technical Monitor: Dwain A. Deets, NASA Dryden Flight Research Facility, Edwards, } \\
\text { California. Presented at AIAA 26th Thermophysics Conference, June 24-26, 1991, Honolulu, Hawaii, } \\
\text { Paper \#91-1383. }\end{array}$} \\
\hline \multicolumn{5}{|c|}{$\begin{array}{l}\text { A cryogenic test article, the Generic Research Cryogenic Tank, was designed to qualitatively sim- } \\
\text { ulate the thermal response of transatmospheric vehicle fuel tanks exposed to the environment of } \\
\text { hypersonic flight. One-dimensional and two-dimensional finite-difference thermal models were } \\
\text { developed to simulate the thermal response and assist in the design of the Generic Research Cryogenic } \\
\text { Tank. The one-dimensional thermal analysis determined the required insulation thickness to meet the } \\
\text { thermal design criteria and located the purge jacket to eliminate the liquefaction of air. The two- } \\
\text { dimensional thermal analysis predicted the temperature gradients developed within the pressure-vessel } \\
\text { wall, estimated the cryogen boiloff, and showed the effects the ullage condition has on pressure-vessel } \\
\text { temperatures. The degree of ullage mixing, location of the applied high-temperature profile, and the } \\
\text { purge gas influence on insulation thermal conductivity had significant effects on the thermal behavior } \\
\text { of the Generic Research Cryogenic Tank. In addition to analysis results, a description of the Generic } \\
\text { Research Cryogenic Tank and the role it will play in future thermal structures and transatmospheric } \\
\text { vehicle research at the NASA Dryden Flight Research Facility is presented. }\end{array}$} \\
\hline \multicolumn{2}{|c|}{$\begin{array}{l}\text { 17. Key Words (Suggested by Author(s)) } \\
\text { Cryogenics, Heat transfer, Hydrogen, NASP, } \\
\text { Numerical analysis, Propellant tanks, } \\
\text { Thermal insulation }\end{array}$} & $\begin{array}{l}\text { 18. Distribu } \\
\text { Uncla }\end{array}$ & - Unlimited & 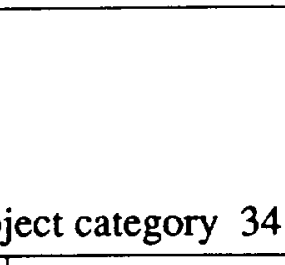 \\
\hline $\begin{array}{l}\text { 19. Security Classif. (of this report) } \\
\text { Unclassified }\end{array}$ & $\begin{array}{l}\text { 20. Security Cla } \\
\text { Unclassi }\end{array}$ & (s page) & $\begin{array}{l}\text { 21. No. of Pages } \\
21\end{array}$ & $\begin{array}{r}\text { 22. Price } \\
\mathrm{A} 02\end{array}$ \\
\hline
\end{tabular}

